CLINICAL STUDY

\title{
Ambulatory arterial stiffness indexes in acromegaly
}

Francesca Dassie*, Andrea Grillo ${ }^{1, *}$, Renzo Carretta ${ }^{1}$, Bruno Fabris ${ }^{1}$, Loredana Macaluso ${ }^{1}$, Moreno Bardelli ${ }^{1}$, Chiara Martini, Agostino Paoletta ${ }^{2}$, Roberto Vettor, Nicola Sicolo, Francesco Fallo and Pietro Maffei

Department of Medical and Surgical Sciences, University of Padova, Via Ospedale 105, 35128 Padova, Italy, ${ }^{1}$ Department of Medical, Surgical and Health Sciences, University of Trieste, Trieste, Italy and ${ }^{2}$ Endocrinology Outpatient Service, Cittadella Hospital, Cittadella, Italy

(Correspondence should be addressed to P Maffei; Email: pietromaffei@libero.it)

*(F Dassie and A Grillo contributed equally to this work)

\begin{abstract}
Objective: Acromegaly is associated with increased cardiovascular morbidity and mortality and with specific heart and vascular abnormalities. The aim of our study was to investigate arterial stiffness using the ambulatory arterial stiffness index (AASI) and symmetric AASI (Sym-AASI), two indexes derived from 24-h ambulatory blood pressure monitoring (ABPM), in a group of normotensive and hypertensive patients with active acromegaly, compared with normotensive controls (NOR-CTR) or hypertensive controls (HYP-CTR).

Subjects and methods: Ninety-six consecutive patients with active acromegaly (46 males, mean age $49 \pm 14$ years) underwent 24-h ABPM and evaluation of cardiovascular risk factors. Based on ABPM measurement, acromegalic patients were divided into 64 normotensive (normotensive acromegalic patients (NOR-ACRO)) and 32 hypertensive (hypertensive acromegalic patients (HYP-ACRO)) patients, and were compared with 35 normotensive (NOR-CTR) and 34 hypertensive (HYP-CTR) age-, sex,- and ABPM-matched control subjects.

Results: The AASI and Sym-AASI indexes were significantly higher in acromegalic patients than in controls, either in the normotensive (NOR-ACRO vs NOR-CTR, $P<0.0001$ for AASI and $P=0.005$ for Sym-AASI) or in the hypertensive (HYP-ACRO vs HYP-CTR, $P=0.01$ for AASI and $P=0.01$ for SymAASI) group. Multiple logistic regression analysis showed a significant association of the highest AASI tertile with serum IGF1 $(P=0.034)$ in the whole acromegalic group.

Conclusion: AASIs are increased in acromegaly, independent of blood pressure (BP) elevation, and may have an important role in predicting cardiovascular risk in this disease.
\end{abstract}

European Journal of Endocrinology 166 199-205

\section{Introduction}

Acromegaly is caused by hypersecretion of a somatotropic pituitary adenoma of $\mathrm{GH}$, which acts through the insulin-like growth factor 1 (IGF1), leading to multiple systemic complications. In fact, in acromegalic patients, there is an increase in morbidity and mortality rate, largely due to cardiovascular disease $(1,2)$, and new strategies to investigate this problem are welcome. An increased prevalence of major cardiovascular risk factors has an important role in causing functional and structural vascular damage, while a direct pathogenic role of GH/IGF1 is still unclear. Cardiovascular abnormalities in uncomplicated acromegalics, where coexisting risk factors are not present $(3,4,5)$, and the improvement of cardiac function after suppression of GH excess (6), both support this hypothesis. Alterations of the vascular system include endothelial dysfunction (7) and a specific cardiomyopathy (8) characterized by left ventricular concentric hypertrophy and diastolic dysfunction. The incidences of coronary artery atherosclerosis (9) and myocardial infarction (10) are, however, similar to those found in the general population.

Arterial stiffness, which can be measured in different ways, has proved to be an independent predictor of adverse cardiovascular outcome (11). Few studies have focused on arterial stiffness in acromegaly, all using pulse wave analysis, with contrasting results $(12,13$, 14). The aim of our study was to investigate arterial stiffness using the ambulatory arterial stiffness index (AASI) and symmetric AASI (Sym-AASI), two indexes derived from $24 \mathrm{~h}$ ambulatory blood pressure monitoring $(A B P M)(15,16)$, in a group of normotensive and hypertensive patients with active acromegaly, compared with normotensive controls (NOR-CTR) or hypertensive controls (HYP-CTR). These two indexes have been shown to be good predictors of cardiovascular morbidity and mortality $(17,18)$, are independently associated with target organ damage (19), and express the interaction of hemodynamic and atherosclerotic factors in increasing cardiovascular burden (20). 


\section{Subjects and methods}

\section{Study population}

Ninety-six patients (46 males, mean age $49 \pm 14$ years) with active acromegaly were studied. Active acromegaly was defined in patients presenting with the typical clinical features, by high serum GH levels (mean of three serum GH baseline samples $>2.5 \mu \mathrm{g} / \mathrm{l}$ ) or $\mathrm{GH}$ not suppressible by the oral glucose tolerance test $(\mathrm{GH}>1.0 \mu \mathrm{g} / \mathrm{l})$, in association with high levels of IGF1 (according to age and gender normal values) and the presence of a pituitary adenoma on magnetic resonance imaging (21). The age of patients at diagnosis was between 12 and 71 years, with a mean age of $40 \pm 15.5$ years.

Forty-three patients were studied with ABPM at diagnosis of acromegaly, while 53 were studied in a later period of time during follow-up evaluation. At the time of ABPM study, acromegalic patients had no washout from antihypertensive or GH/IGF1 suppressive medications. Specifically, 40 out of $96(42 \%)$ patients were on antihypertensive therapy, $19(20 \%)$ with an association of two or more drugs. Forty-one acromegalic patients already had transsphenoidal adenomectomy and 11 patients had radiotherapy; 32 patients were on treatment with somatostatin analogs, three with pegvisomant, and two with cabergoline.

Age- and sex-matched control subjects were recruited from consecutive patients evaluated at the Hypertension Outpatient Clinic in Trieste University Hospital for the diagnosis of hypertension (Table 1). On the basis of 24-h ABPM values, the hypertensive acromegalic subjects $(n=32)$ were matched with a group of HYP-CTR $(n=34)$ selected on purpose within a larger essential hypertensive population, and off treatment at the time of the study. NOR-CTR $(n=35)$ were the patients who, at the end of the evaluation, showed normal blood pressure (BP) values.

Informed consent was obtained from all cases. The study was approved by Institutional Ethics Committees.

\section{Anthropometric and laboratory methods}

In all individuals, anthropometric measures and blood samples for biochemical parameters were obtained in the morning after overnight fasting, at the time of ABPM study.

As previously reported (22), serum GH was measured by chemiluminescence with reagents supplied by GH IMMUNOLITE 2000 (Siemens, Muenchen, Germany). The detection limit was $0.05 \mu \mathrm{g} / \mathrm{l}$, with intra- and inter-assay variation coefficients of 4.0 and $6.5 \%$ respectively. Serum IGF1 was measured by chemiluminescence with reagents supplied by DiaSorin Liaison (Saluggia (VC), Italy). The detection limit was $0.6 \mu \mathrm{g} / \mathrm{l}$, with intra- and inter-assay variation coefficients of 5.6 and $7.7 \%$ respectively. All other biochemical variables were assayed in plasma or serum using standard methods.

\section{Ambulatory BP measurement}

Twenty-four hour ABPM measurement was carried out in acromegalic patients with the A\&D Takeda TM-2430 device (Asahi, Japan) (23). In control patients, ABPM measurement was obtained using SpaceLab 90207 instrumentation (Redmond, WA, USA). Both the BP measuring automated devices were validated in accordance with the criteria of the International Protocol of the European Society of Hypertension (ESH) (24).

Devices were programmed to perform records every $15 \mathrm{~min}$ in $24 \mathrm{~h}$ or alternatively every $15 \mathrm{~min}$ in daytime and every 20 min in nighttime. Daytime and nighttime periods were considered as the intervals from 0800 to $2200 \mathrm{~h}$ and from midnight to $0600 \mathrm{~h}$ respectively. During the recordings, patients were instructed to follow their usual activity and to report sleep duration. The arm cuff was positioned on the non-dominant upper limb. The readings of the automatic recorder were checked against those obtained with a mercury sphygmomanometer at the beginning and end of each 24-h monitoring session; a difference within

Table 1 Age, gender, and anthropometric differences among normotensive patients with acromegaly (NOR-ACRO), hypertensive patients with acromegaly (HYP-ACRO), normotensive controls (NOR-CTR), and hypertensive controls (HYP-CTR).

\begin{tabular}{|c|c|c|c|c|c|}
\hline & NOR-CTR & HYP-CTR & NOR-ACRO & HYP-ACRO & $P$ values \\
\hline$n$ & 35 & 34 & 64 & 32 & $P=\mathrm{NS}$ \\
\hline Age & $48.1 \pm 6.7$ & $54.1 \pm 12.4$ & $46.5 \pm 14.0$ & $54.8 \pm 12.8$ & $\begin{array}{l}P_{\mathrm{NOR}}=\mathrm{NS} \\
P_{\mathrm{HYP}}=\mathrm{NS}\end{array}$ \\
\hline Gender (male, \%) & 43 & 26 & 47 & 26 & $\begin{array}{l}P_{\mathrm{NOR}}=\mathrm{NS} \\
P_{\mathrm{HYP}}=\mathrm{NS}\end{array}$ \\
\hline Weight (kg) & $72.5 \pm 9.9$ & $67.0 \pm 2.7$ & $81.6 \pm 15.3$ & $84.1 \pm 19.2$ & $\begin{array}{l}P_{\mathrm{NOR}}=0.002 \\
P_{\mathrm{HYP}}=0.0001\end{array}$ \\
\hline Height $(\mathrm{cm})$ & $169.1 \pm 0.7$ & $168.3 \pm 0.1$ & $171.4 \pm 0.1$ & $162.0 \pm 0.3$ & $\begin{array}{l}P_{\mathrm{NOR}}<0.0001 \\
P_{\mathrm{HYP}}<0.0001\end{array}$ \\
\hline BMI $\left(\mathrm{kg} / \mathrm{m}^{2}\right)$ & $25.2 \pm 3.2$ & $23.7 \pm 2.7$ & $27.9 \pm 4.4$ & $30.4 \pm 6.8$ & $\begin{array}{l}P_{\mathrm{NOR}}=0.001 \\
P_{\mathrm{HYP}}<0.0001\end{array}$ \\
\hline
\end{tabular}

$P_{\text {NOR }}$, NOR-CTR vs NOR-ACRO; $P_{\text {HYP }}$, HYP-CTR vs HYP-ACRO. BMI, body mass index. 
$\pm 5 \mathrm{mmHg}$ was considered an adequate agreement between the two methods. Measured values of systolic $\mathrm{BP}$, diastolic BP, and heart rate were downloaded using custom software. BP and heart rate measurements were excluded from the analysis when they were missing or labeled as technically erroneous by the monitor software. Records containing $<70 \%$ successful readings were rejected. In every subject, $24-\mathrm{h}$ ambulatory $\mathrm{BP}$ mean and daytime $\mathrm{BP}$ and nighttime $\mathrm{BP}$ means were calculated.

According to the 2007 ESH-European Society of Cardiology Guidelines for the management of arterial hypertension (25), on the basis of ABPM measurement, patients were divided into 64 normotensive (normotensive acromegalic patients (NOR-ACRO)) and 32 hypertensive (hypertensive acromegalic patients (HYP-ACRO)) patients, and were compared with 35 normotensive (NOR-CTR) and 34 hypertensive (HYP-CTR) control subjects.

\section{Arterial stiffness indexes}

Calculations of AASI and Sym-AASI were derived from individual ABPM recordings. The AASI index was calculated according to the following formula: $1-$ the regression slope of diastolic pressure on systolic BP. The Sym-AASI index was calculated using the simplified formulation published by Gavish et al. (16): Sym-AASI $=1-($ correlation coefficient/regression slope of systolic on diastolic BP).

\section{Statistical analysis}

Data were expressed as mean \pm s.D. for continuous variables and as proportion for categorical variables. Statistical significance between groups was assessed in normally distributed data by Student's $t$-test for independent samples and in non-normally distributed data by Mann-Whitney $U$ test. Categorical variables were analyzed by the $\chi^{2}$ analysis or Fisher's exact test, when appropriate. Statistical comparisons among multiple groups were made using ANOVA, and the following variables were considered independently: age, 24-h systolic and diastolic BP, heart rate, body mass index (BMI), fasting glucose levels, low-density lipoprotein cholesterol (LDL-C), AASI, and Sym-AASI. In the acromegalic population, linear regression analysis was used to explore the relationship between AASI and anthropometric and disease activity (i.e. IGF1/GH concentration) parameters and a multivariate logistic regression analysis was carried out to evaluate the association of these variables with AASI and Sym-AASI tertiles. Statistical significance was assumed if the null hypothesis could be rejected at $P<0.05$. All statistical analyses were performed using Statview for Windows (version 5.0; SAS Institute, Inc., Cary, NC, USA).

\section{Results}

All acromegalic patients were studied during disease activity, and their mean GH and IGF1 values were $27.6 \pm 70.4$ and $706.6 \pm 308.4 \mu \mathrm{g} / \mathrm{l}$ respectively.

Table 2 Clinical and biochemical differences among normotensive patients with acromegaly (NOR-ACRO), hypertensive patients with acromegaly (HYP-ACRO), normotensive controls (NOR-CTR), and hypertensive controls (HYP-CTR).

\begin{tabular}{|c|c|c|c|c|c|}
\hline & NOR-CTR & HYP-CTR & NOR-ACRO & HYP-ACRO & $P$ values \\
\hline $\begin{array}{l}\text { 24-h systolic/ } \\
\text { diastolic BP }(\mathrm{mmHg})\end{array}$ & $\begin{array}{r}116.3 \pm 5.8 / \\
71.5 \pm 6.8\end{array}$ & $\begin{array}{r}134.1 \pm 8.3 / \\
82.7 \pm 6.1\end{array}$ & $\begin{array}{r}115.6 \pm 7.7 / \\
70.0 \pm 5.6\end{array}$ & $\begin{array}{r}136.2 \pm 8.2 / \\
83.6 \pm 8.2\end{array}$ & $\begin{array}{l}P_{\text {NOR-systolic BP }}=\mathrm{NS} \\
P_{\text {NOR-diastolic } \mathrm{BP}}=\mathrm{NS} \\
P_{\text {HYP-systolic } \mathrm{BP}}=\mathrm{NS} \\
P_{\text {HYP-diastolic } \mathrm{BP}}=\mathrm{NS}\end{array}$ \\
\hline $\begin{array}{l}\text { Daytime systolic/ } \\
\text { diastolic BP (mmHg) }\end{array}$ & $\begin{array}{r}118.4 \pm 5.6 / \\
73.5 \pm 7.4\end{array}$ & $\begin{array}{r}139.4 \pm 7.8 / \\
86.1 \pm 6.3\end{array}$ & $\begin{array}{r}119.9 \pm 8.4 / \\
74.3 \pm 9.7\end{array}$ & $\begin{array}{r}139.7 \pm 8.2 / \\
86.3 \pm 8.6\end{array}$ & $\begin{array}{l}P_{\text {NOR-systolic } \mathrm{BP}}=\mathrm{NS} \\
P_{\mathrm{NOR}-\text { diastolic } \mathrm{BP}}=\mathrm{NS} \\
P_{\text {HYP-systolic BP }}=\mathrm{NS} \\
P_{\text {HYP-diastolic BP }}=\mathrm{NS}\end{array}$ \\
\hline $\begin{array}{l}\text { Nighttime systolic/ } \\
\text { diastolic BP }(\mathrm{mmHg})\end{array}$ & $\begin{array}{r}109.3 \pm 9.0 / \\
64.6 \pm 7.3\end{array}$ & $\begin{array}{r}126.4 \pm 8.2 / \\
75.9 \pm 6.7\end{array}$ & $\begin{array}{r}106.8 \pm 9.1 / \\
63.0 \pm 6.8\end{array}$ & $\begin{array}{c}128.3 \pm 11.5 / \\
77.7 \pm 9.3\end{array}$ & $\begin{array}{l}P_{\text {NOR-systolic BP }}=\mathrm{NS} \\
P_{\text {NOR-diastolic } \mathrm{BP}}=\mathrm{NS} \\
P_{\text {HYP-systolic BP }}=\mathrm{NS} \\
P_{\text {HYP-diastolic } \mathrm{BP}}=\mathrm{NS}\end{array}$ \\
\hline 24-h heart rate (bpm) & $72 \pm 12$ & $73 \pm 7$ & $71 \pm 9$ & $72 \pm 10$ & $\begin{array}{l}P_{\mathrm{NOR}-\text { diastolic }}=\mathrm{NS}-\mathrm{IS} \\
P_{\mathrm{HYP}}=\mathrm{NS}\end{array}$ \\
\hline $\mathrm{GH}(\mu \mathrm{g} / \mathrm{ml})$ & - & - & $19.3 \pm 41.0$ & $28.3 \pm 58.7$ & \\
\hline IGF1 ( $\mu \mathrm{g} / \mathrm{ml})$ & - & - & $698.8 \pm 344.1$ & $709.0 \pm 240.4$ & \\
\hline Fasting glucose $(\mathrm{mmol} / \mathrm{l})$ & $5.32 \pm 0.59$ & $4.95 \pm 0.66$ & $6.04 \pm 1.50$ & $6.58 \pm 2.38$ & $\begin{array}{l}P_{\mathrm{NOR}}=0.008 \\
P_{\mathrm{HYP}}=0.0002\end{array}$ \\
\hline LDL-C (mmol/l) & $3.86 \pm 0.86$ & $3.18 \pm 0.70$ & $3.17 \pm 0.82$ & $3.37 \pm 0.69$ & $\begin{array}{l}P_{\mathrm{NOR}}=0.0002 \\
P_{\mathrm{HYP}}=\mathrm{NS}\end{array}$ \\
\hline \multicolumn{6}{|l|}{ Medication } \\
\hline For hypertension & 0 & 0 & 20 & 20 & \\
\hline For acromegaly & 0 & 0 & 28 & 9 & \\
\hline
\end{tabular}

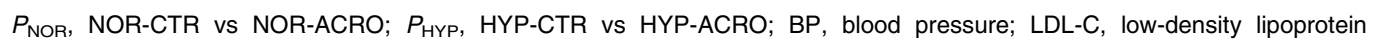
cholesterol; IGF1, insulin-like growth factor 1 . 

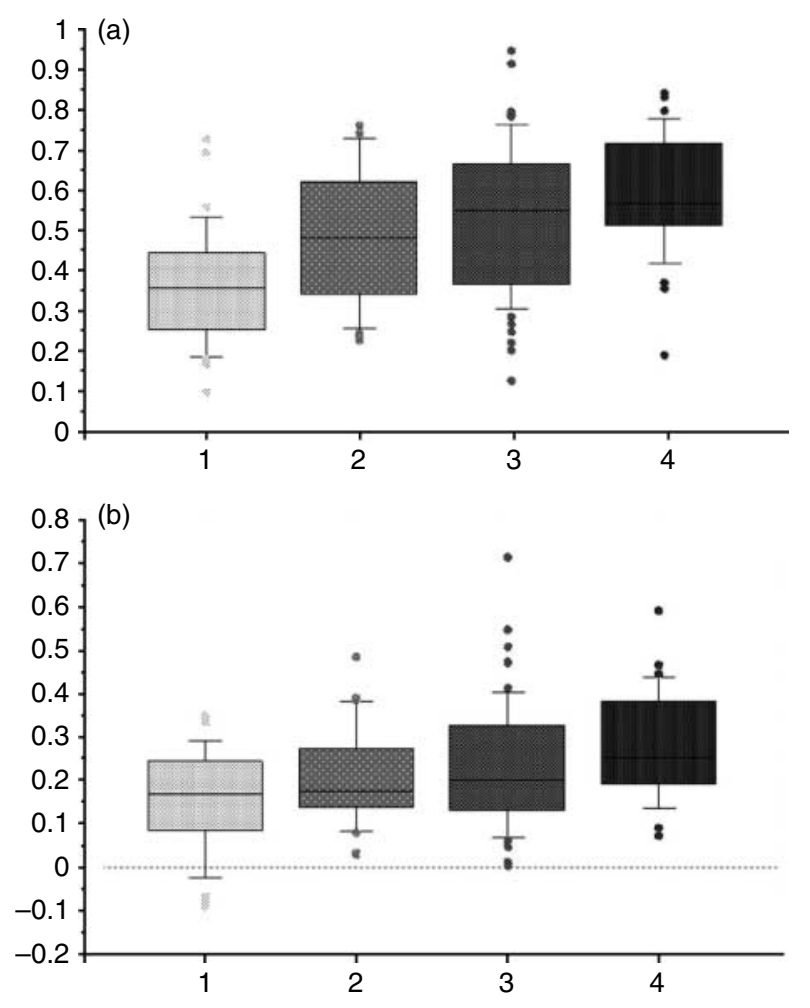

Figure 1 Box plots including lower and upper quartiles, median (50th percentile), extreme data, and S.D. above and below the mean of (a) AASI and (b) Sym-AASI in controls (1, NOR-CTR; 2, HYPCTR) and in acromegalic patients (3, NOR-ACRO; 4, HYP-ACRO). Significant $P$ values for AASI: NOR-CTR vs HYP-CTR, $P=0.001$; NOR-CTR vs NOR-ACRO, $P<0.0001$; HYP-CTR vs HYP-ACRO, $P=0.01$. Significant $P$ values for Sym-AASI: NOR-CTR vs NORACRO, $P=0.003$; HYP-CTR vs HYP-ACRO, $P=0.01$.

Age and sex were similar $(P=\mathrm{NS})$ in the entire acromegalic ( $49 \pm 14$ years, 46 males/50 females) and in the entire control group $(51.1 \pm 9.6$ years, 25 males/44 females). Twenty-four hour systolic BP, diastolic BP, and heart rate did not differ between the entire acromegalic population and control population $(125.2 \pm 7.1$ vs $125.9 \pm 7.9 \mathrm{mmHg}, 76.8 \pm 6.9$ vs $77.1 \pm 6.1 \mathrm{mmHg}$, and $72.1 \pm 10.1$ beats per minute (bpm) vs $73.1 \pm 9.6 \mathrm{bpm}$ respectively; $P=\mathrm{NS}$ ). Acromegalic patients had a mean weight of $82.4 \pm 21.2 \mathrm{~kg}$ and a BMI of $28.6 \pm 5.5 \mathrm{~kg} / \mathrm{m}^{2}$, which were significantly higher in comparison with controls (weight $69.7 \pm 11.3 \mathrm{~kg}, P<0.0001$ and BMI $24.4 \pm 3.0 \mathrm{~kg} / \mathrm{m}^{2}$, $P<0.0001$ respectively). Regarding metabolic parameters, fasting glucose in the entire acromegalic group was significantly higher than that in the entire control group $(2.94 \pm 0.89$ vs $2.39 \pm 0.30 \mathrm{mmol} / \mathrm{l}$, $P<0.0001$ ), while LDL-C was higher in controls than in acromegalic patients $(3.52 \pm 0.86$ vs $3.25 \pm$ $0.77 \mathrm{mmol} / \mathrm{l}, P=0.003$ ).

Table 1 summarizes age, gender, and anthropometric parameters in the different acromegalic and control subgroups. Significant differences for weight, height, and BMI were detected between NOR-ACRO and NOR-CTR as well as between HYP-ACRO and HYP-CTR.

Table 2 summarizes ABPM and biochemical differences among different acromegalic and control subgroups. Mean 24-h as well as daytime and nighttime systolic or diastolic BP, and 24-h heart rate did not differ between NOR-ACRO and NOR-CTR or between HYP-ACRO and HYP-CTR. Fasting glucose was significantly higher in NOR-ACRO and HYP-ACRO than in NOR-CTR and HYP-CTR, respectively, while LDL-C was higher in NOR-ACRO than in NOR-CTR, but not higher in HYP-ACRO than in HYP-CTR. Comparing the AASI, we found that NOR-ACRO had a significantly higher AASI than NOR-CTR $(0.52 \pm 0.17$ vs $0.36 \pm 0.14$, $P<0.0001)$; also, HYP-ACRO had higher AASI than HYP-CTR $(0.59 \pm 0.15$ vs $0.49 \pm 0.17, P=0.011)$. Sym-AASI in both NOR-ACRO $(0.23 \pm 0.14)$ and HYP-ACRO $($ Sym-AASI $=0.28 \pm 0.12)$ were higher than the values in NOR-CTR $(0.15 \pm 0.12)$ and HYP-CTR $(0.20 \pm 0.10 ; P=0.005$ and $P=0.009)$ respectively. Box plots for AASI and Sym-AASI, including lower and upper quartile, median (50th percentile), extreme data, and S.D. above and below the mean are shown in Fig. 1a and b respectively.

In the entire acromegalic group, linear regression analysis did not demonstrate any significant correlation with anthropometric or biochemical parameters, except for a borderline significant association with IGF1 $(P=0.052$; Table 3$)$. The multivariate logistic regression showed a significant association of the highest AASI tertile with IGF1 $(P=0.034$; Table 4$)$.

\section{Discussion}

In this study, we found significantly higher AASI and Sym-AASI in NOR-ACRO and HYP-ACRO, compared with control groups, matched by sex, age, and mean systolic and diastolic 24-h BP.

Recently, detection of early functional and structural changes in the arterial wall has been recommended by various authors as a strong prognostic factor and as an end point in cardiovascular morbidity and mortality (11).

Table 3 Multiple linear regression analysis showing the association of ambulatory arterial stiffness index with anthropometric and biochemical parameters in the entire acromegalic group.

\begin{tabular}{lccc}
\hline & Coeff. & $\boldsymbol{T}$ value & $\boldsymbol{P}$ value \\
\hline MBP & 0.0003 & 0.174 & 0.862 \\
Age & 0.002 & 1.615 & 0.11 \\
BMI & -0.001 & -0.301 & 0.764 \\
Fasting glucose & -0.001 & -1.091 & 0.278 \\
LDL-C & 0.001 & 1.28 & 0.219 \\
GH & 0.0003 & 0.101 & 0.919 \\
IGF1 & 0.0001 & 1.976 & 0.052 \\
\hline
\end{tabular}

MBP, mean blood pressure (24-h diastolic BP $+1 / 3(24-h$ systolic BP $-24-h$ diastolic BP)); BMI, body mass index; LDL-C, low-density lipoprotein cholesterol; IGF1, insulin-like growth factor 1. 
Table 4 Multiple logistic regression analysis showing the association of the highest ambulatory arterial stiffness index tertile with anthropometric and biochemical parameters in the entire acromegalic group.

\begin{tabular}{lccc}
\hline & Coeff. & $\chi^{2}$ & $\boldsymbol{P}$ value \\
\hline MBP & -0.013 & 0.111 & 0.738 \\
Age & 0.044 & 2.984 & 0.841 \\
BMl & -0.031 & 0.221 & 0.638 \\
Fasting glucose & -0.003 & 0.06 & 0.807 \\
LDL-C & 0.01 & 0.855 & 0.355 \\
GH & 0.005 & 0.448 & 0.503 \\
IGF1 & 0.002 & 4.47 & 0.034 \\
\hline
\end{tabular}

MBP, mean blood pressure (24-h diastolic BP $+1 / 3(24-h$ systolic BP $-24-h$ diastolic BP)); BMI, body mass index; LDL-C, low-density lipoprotein cholesterol; IGF1, insulin-like growth factor 1.

The AASI and Sym-AASI are based on the rationale that the relationship between systolic and diastolic BP is dynamic and depends on the functional and structural characteristics of large arteries. Elevation of these indexes shows a larger increase in systolic BP compared with diastolic BP, with changes in distending pressure. This dynamic behavior reflects an intermittent load on the heart and arterial tree, which can lead to organ damage. The AASI has been proposed as an easily available measure of arterial stiffness, when compared with more costly and specialized techniques. Reproducibility of AASI has been found to be lower than that of other types of arterial stiffness measurement techniques (26) and to be moderate in terms of difference between repeat recordings (27). Furthermore, there are still some questions on considering AASI as a good surrogate measure of arterial stiffness $(28,29)$; this parameter has been validated as a predictor of cardiovascular and cerebrovascular outcome in the general population in large cohort studies $(17,18$, $19,20)$. The use of a symmetric regression in diastolic and systolic BP slope, proposed by Gavish et al. (16), led to the definition of Sym-AASI, which is independent of nocturnal BP pattern and might provide a better approach for estimating arterial stiffness.

Smith et al. (12) observed an increased augmentation index (a measure of arterial stiffness) in 16 NOR-ACRO, when compared with healthy controls, with a partial reduction after 3 months of GH suppression therapy. Sakai et al. (13) reported no change in pulse wave velocity (a different measure of arterial stiffness) in patients with active acromegaly after transsphenoidal surgery, despite improved endothelium-mediated dilation. More recently, Paisley et al. (14) reported a significantly increased pulse wave velocity but unaltered intima-media thickness in 56 patients with acromegaly when compared with controls, considering this phenomenon as a pressure-related stiffening of the arterial wall.

In our study, age, an important factor associated with increased arterial stiffening (30), did not differ when comparing NOR-ACRO with NOR-CTR or HYP-ACRO with HYP-CTR; thus, this parameter was reasonably excluded as a possible confounder. Heart rate, recently identified as an additional confounder of AASI (31), was similar in the four groups of patients.

Among the other possible factors affecting arterial wall structure and function, comorbidities can play an important role in acromegaly. The GH/IGF1 overproduction could in fact produce vascular detrimental effects in addition to those caused by the presence per se of various cardiovascular risk factors such as hypertension, dyslipidemia, and/or altered glucose metabolism (8, 23). Hypertension is considered to be the most important factor in determining alterations of the vascular wall, leading to arterial stiffness (32). In acromegaly, imbalance of the GH-IGF1 axis leads through various pathogenic mechanisms to an increased prevalence of hypertension (8). In our study, we found an alteration of arterial stiffness independent of BP, since NOR-ACRO had significantly increased AASI and Sym-AASI when compared with matched NOR-CTR. In our HYP-ACRO, antihypertensive therapy was not discontinued due to ethical reasons. However, medical treatment for hypertension is known to decrease large artery stiffening (11). Although this could appear as a limitation in the design of the study, our data showing increased AASI and SymAASI in HYP-ACRO compared with HYP-CTR reinforce the hypothesis that hypertension per se may not have a specific role in increasing arterial stiffness in acromegaly. Fasting glucose and BMI in our acromegalic patients were indeed higher than in controls. BMI, impaired glucose tolerance, and diabetes are associated with higher arterial stiffness in the general population (33, $34,35)$, and their role in contributing to increased arterial stiffness in the acromegalic population cannot be completely ruled out. At variance, LDL-C levels were lower in our NOR-ACRO compared with NOR-CTR; a possible contribution of higher lipoprotein(a), found to be associated with acromegaly (36), should be considered. Also, a direct influence of GH/IGF1 excess in altering AASI and Sym-AASI seems to be not excluded by our findings. In fact, IGF1 was the only parameter related to AASI at multiple linear regression analysis, and IGF1 was significantly associated with the highest AASI tertile at multivariate logistic regression analysis in the acromegalic group. In this regard, the GH/IGF1 excess is thought to promote migration and proliferation of vascular smooth muscle cells (37) and to produce in animal models an increase in collagen type III (38), resulting in derangement of vessel mechanical properties.

In conclusion, our study shows that AASIs are increased in acromegaly, independent of BP elevation, and may have an important role in predicting cardiovascular risk in this disease.

\section{Declaration of interest}

The authors declare that there is no conflict of interest that could be perceived as prejudicing the impartiality of the research reported. 


\section{Funding}

This research did not receive any specific grant from any funding agency in the public, commercial or not-for-profit sector.

\section{References}

1 Wright AD, Hill DM, Lowy C \& Russell-Fraser T. Mortality in acromegaly. Quarterly Journal of Medicine 1970 153 1-16.

2 Orme SM, McNally RJQ, Cartwright RA \& Belchetz PE. Mortality and cancer incidence in acromegaly: a retrospective cohort study. Journal of Clinical Endocrinology and Metabolism 1998 83 2730-2734. (doi:10.1210/jc.83.8.2730)

3 Fazio S, Cittadini A, Biondi B, Palmieri EA, Riccio G, Bone F, Oliviero U \& Saccà L. Cardiovascular effects of short-term growth hormone hypersecretion. Journal of Clinical Endocrinology and Metabolism 200085 179-182. (doi:10.1210/jc.85.1.179)

4 Maison P, Demolis P, Young J, Schaison G, Giudicelli J-F \& Chanson P. Vascular reactivity in acromegalic patients: preliminary evidence for regional endothelial dysfunction and increased sympathetic vasoconstriction. Clinical Endocrinology 200053 445-451. (doi:10.1046/j.1365-2265.2000.01127.x)

5 Colao A, Spinelli L, Cuocolo A, Spiezia S, Pivonello R, di Somma C, Bonaduce D, Salvatore M \& Lombardi G. Cardiovascular consequences of early-onset growth hormone excess. Journal of Clinical Endocrinology and Metabolism 200287 3097-3104. (doi:10.1210/jc.87.7.3097)

6 Merola B, Cittadini A, Colao A, Ferone D, Fazio S, Sabatini D, Biondi B, Saccà L \& Lombardi G. Chronic treatment with the somatostatin analog octreotide improves cardiac abnormalities in acromegaly. Journal of Clinical Endocrinology and Metabolism 1993 77 790-793. (doi:10.1210/jc.77.3.790)

7 Brevetti G, Marzullo P, Silvestro A, Pivonello R, Oliva G, di Somma C, Lombardi G \& Colao A. Early vascular alterations in acromegaly. Journal of Clinical Endocrinology and Metabolism 2002 87 3174-3179. (doi:10.1210/jc.87.7.3174)

8 Saccà L, Cittadini A \& Fazio S. Growth hormone and the heart. Endocrine Reviews 199415 555-573. (doi:10.1210/edrv-15-5-555)

9 Colao A, Ferone D, Marzullo P \& Lombardi G. Systemic complications of acromegaly: epidemiology, pathogenesis, and management. Endocrine Reviews 200425 102-152. (doi:10. 1210/er.2002-0022)

10 Akutsu H, Kreutzer J, Wasmeier G, Ropers D, Rost C, Möhlig M, Wallaschofski H, Buchfelder M \& Schöfl C. Acromegaly per se does not increase the risk for coronary artery disease. European Journal of Endocrinology 2010162 879-886. (doi:10.1530/EJE09-0945)

11 Laurent S, Cockcroft J, Van Bortel L, Boutouyrie P, Giannattasio C, Hayoz D, Pannier B, Vlachopoulos C, Wilkinson I \& StruijkerBoudier H. European network for non-invasive investigation of large arteries. Expert consensus document on arterial stiffness: methodological issues and clinical applications. European Heart Journal 200627 2588-2605. (doi:10.1093/eurheartj/ehl254)

12 Smith JC, Lane H, Davies N, Evans LM, Cockcroft J, Scanlon MF \& Davies JS. The effects of depot long-acting somatostatin analog on central aortic pressure and arterial stiffness in acromegaly. Journal of Clinical Endocrinology and Metabolism 200388 2556-2561. (doi:10.1210/jc.2002-021746)

13 Sakai H, Tsuchiya K, Nakayama C, Iwashima F, Izumiyama H, Doi $M$, Yoshimoto $T$, Tsujino $M$, Yamada $S$ \& Hirata $Y$. Improvement of endothelial dysfunction in acromegaly after transsphenoidal surgery. Endocrine Journal $2008 \mathbf{5 5} 853-859$. (doi:10.1507/endocrj.K07E-125)

14 Paisley AN, Banerjee M, Rezai M, Schofield RE, Balakrishnannair S, Herbert A, Lawrance JA, Trainer PJ \& Cruickshank JK. Changes in arterial stiffness but not carotid intimal thickness in acromegaly. Journal of Clinical Endocrinology and Metabolism 201196 1486-1492. (doi:10.1210/jc.20102225)
15 Li Y, Wang JG, Dolan E, Gao PJ, Guo HF, Nawrot T, Stanton AV, Zhu DL, O'Brien E \& Staessen JA. Ambulatory arterial stiffness index derived from 24-hour ambulatory blood pressure monitoring. Hypertension $2006 \mathbf{4 7} 359-364$. (doi:10.1161/01.HYP. $0000200695.34024 .4 \mathrm{c})$

16 Gavish B, Ben-Dov IZ \& Bursztyn M. Linear relationship between systolic and diastolic blood pressure monitored over $24 \mathrm{~h}$ : assessment and correlates. Journal of Hypertension 200826 199-209. (doi:10.1097/HJH.0b013e3282f25b5a)

17 Dolan E, Thijs L, Li Y, Atkins N, McCormack P, McClory S, O'Brien E, Staessen JA \& Stanton AV. Ambulatory arterial stiffness index as a predictor of cardiovascular mortality in the Dublin Outcome Study. Hypertension 200647 365-370. (doi:10.1161/ 01.HYP.0000200699.74641.c5)

18 Kikuya M, Staessen JA, Ohkubo T, Thijs L, Metoki H, Asayama K, Obara T, Inoue R, Li Y, Dolan E, Hoshi H, Hashimoto J, Totsune K, Satoh H, Wang JG, O'Brien E \& Imai Y. Ambulatory arterial stiffness index and 24-hour ambulatory pulse pressure as predictors of mortality in Ohasama, Japan. Stroke $2007 \mathbf{3 8}$ 1161-1166. (doi:10.1161/01.STR.0000259604.67283.69)

19 Leoncini G, Ratto E, Viazzi F, Vaccaro V, Parodi A, Falqui V, Conti N, Tomolillo C, Deferrari G \& Pontremoli R. Increased ambulatory arterial stiffness index is associated with target organ damage in primary hypertension. Hypertension $2006 \mathbf{4 8} 397-403$. (doi:10. 1161/01.HYP.0000236599.91051.1e)

20 Ben-Dov IZ, Gavish B, Kark JD, Mekler J \& Bursztyn M. A modified ambulatory arterial stiffness index is independently associated with all-cause mortality. Journal of Human Hypertension 200822 761-766. (doi:10.1038/jhh.2008.50)

21 Melmed S. Medical progress: Acromegaly. New England Journal of Medicine 2006 355 2558-2573. (doi:10.1056/ NEJMra062453)

22 Mulatero P, Veglio F, Maffei P, Bondanelli M, Bovio S, Daffara F, Leotta G, Angeli A, Calvo C, Martini C, degli Uberti EC \& Terzolo M. CYP11B2 - 344T/C gene polymorphism and blood pressure in patients with acromegaly. Journal of Clinical Endocrinology and Metabolism 200691 5008-5012. (doi:10.1210/jc.2006-0049)

23 Fallo F, Barzon L, Boscaro M, Casiglia E \& Sonino N. Effect of octreotide on 24-hour blood pressure profile in acromegaly. American Journal of Hypertension 199811 591-596. (doi:10. 1016/S0895-7061(98)00029-6)

24 O'Brien E, Atkins N, Stergiou G, Karpettas N, Parati G, Asmar R, Imai Y, Wang J, Mengden T \& Shennan A. European Society of Hypertension International Protocol revision for the validation of blood pressure measuring devices in adults. Blood Pressure Monitoring 201015 23-38. (doi:10.1097/MBP. 0b013e3283360e98)

25 Mancia G, De Backer G, Dominiczak A, Cifkova R, Fagard R, Germano G, Grassi G, Heagerty AM, Kjeldsen SE, Laurent S, Narkiewicz K, Ruilope L, Rynkiewicz A, Schmieder RE, Boudier HA \& Zanchetti A. ESH-ESC Task Force on the Management of Arterial Hypertension Guidelines for the management of arterial hypertension: the task force for the management of arterial hypertension of the European Society of Hypertension (ESH) and of the European Society of Cardiology (ESC). Journal of Hypertension 200725 1105-1187. (doi:10.1097/HJH.0b013e3281fc975a)

26 Laugesen E, Hansen KW, Knudsen ST, Erlandsen M, Ebbehøj E \& Poulsen PL. Reproducibility of the ambulatory arterial stiffness index in patients with type 1 diabetes mellitus. Blood Pressure Monitoring 201015 18-22. (doi:10.1097/MBP.0b013e3283 3531f9)

27 Dechering DG, van der Steen MS, Adiyaman A, Thijs L, Deinum J, Li Y, Dolan E, Akkermans RP, Richart T, Hansen TW, Kikuya M, Wang J, O'Brien E, Thien T \& Staessen JA. Reproducibility of the ambulatory arterial stiffness index in hypertensive patients. Journal of Hypertension 200826 1993-2000. (doi:10.1097/ HJH.Ob013e328309ee4c)

28 Schillaci G \& Parati G. Ambulatory arterial stiffness index: merits and limitations of a simple surrogate measure of arterial compliance. Journal of Hypertension 200826 182-185. (doi:10. 1097/HJH.0b013e3282f52fb9) 
29 Schillaci G, Parati G, Pirro M, Pucci G, Mannarino MR, Sperandini L \& Mannarino E. Ambulatory arterial stiffness index is not a specific marker of reduced arterial compliance. Hypertension 2007 49 986-991. (doi:10.1161/HYPERTENSIONAHA.106.082248)

30 McEniery CM, Yasmin, Hall IR, Qasem A, Wilkinson IB \& Cockcroft JR. Normal vascular aging: differential effects on wave reflection and aortic pulse wave velocity: the Anglo Cardiff Collaborative Trial (ACCT). Journal of the American College of Cardiology 200546 1753-1760. (doi:10.1016/j.jacc.2005.07. 037)

31 Kips J, Vermeersch S, Reymond P, Boutouyrie P, Stergiopulos N, Laurent S, Van Bortel L \& Segers P. Ambulatory arterial stiffness index (AASI): a useful marker of arterial stiffness? Journal of Hypertension 201129 (e-supplement A) e70.

32 Simon AC, Levenson J, Bouthier J, Safar ME \& Avolio AP. Evidence of early degenerative changes in large arteries in human essential hypertension. Hypertension 19857 675-680. (doi: 10.1161/01. HYP.7.5.675)

33 Kolade OO, O’Moore-Sullivan TM, Stowasser M, Coombes JS, Fassett RG, Marwick TH \& Sharman JE. Arterial stiffness, central blood pressure and body size in health and disease. International Journal of Obesity 2012 In press. (doi:10.1038/ijo.2011.79)

34 Henry RM, Kostense PJ, Spijkerman AM, Dekker JM, Nijpels G, Heine RJ, Kamp O, Westerhof N, Bouter LM \& Stehouwer CD.
Hoorn Study. Arterial stiffness increases with deteriorating glucose tolerance status: the Hoorn Study. Circulation $2003 \mathbf{1 0 7} 2089$ 2095. (doi:10.1161/01.CIR.0000065222.34933.FC)

35 Schram MT, Henry RM, van Dijk RA, Kostense PJ, Dekker JM, Nijpels G, Heine RJ, Bouter LM, Westerhof N \& Stehouwer CD. Increased central artery stiffness in impaired glucose metabolism and type 2 diabetes: the Hoorn Study. Hypertension 2004 43 176-181. (doi:10.1161/01.HYP.0000111829.46090.92)

36 Maffei P, Sicolo N \& Plebani M. Lipoprotein(a) in acromegaly. Annals of Internal Medicine 1999130 537-538.

37 Chen Y, Capron L, Magnusson JO, Wallby LA \& Arnqvist HJ. Insulin-like growth factor-1 stimulates vascular smooth muscle cell proliferation in rat aorta in vivo. Growth Hormone $\mathcal{E}$ IGF Research 19988 299-303. (doi:10.1016/S1096-6374(98) 80125-1)

38 Brüel A \& Oxlund H. Growth hormone influences the content and composition of collagen in the aorta from old rats. Mechanisms of Ageing and Development 2002123 627-635. (doi:10.1016/ S0047-6374(01)00409-2)

Received 26 September 2011

Revised version received 21 November 2011

Accepted 28 November 2011 